\title{
On Improving the Efficiency and Quality of Meter Reading and Charging
}

\author{
Guo Shujiang, Feng Lei, Cao Huijie, Shan Jia, Miao Hui, Wang Xue, Yang Yingying, Wei \\ Ye, Cao Huiyan, Wang Shuai
}

Fushun Power Supply Company, Liaoning Electric Power Company Limited, State Grid, China, Zip code 113008

Keywords: Meter Reading; charging; electric power enterprise; management

\begin{abstract}
In the management of electric power enterprises, meter reading, accounting and charging are not only three important aspects of electric power marketing, but also the key-point of the work at the same time. This paper puts forward opinion on how to improve the efficiency and quality of meter reading and charging, according to many years' electrical work experience.
\end{abstract}

\section{Introduction}

The space truss structure of the power system is being more and more complicated with the rapid development of electric power industry. The traditional model of meter reading and charging has already can't meet the need of the power system at present, according to the continuously increasing customer requirements for power supply quality. So an urgent problem in the current development of electric power enterprises to be solved is how to realize the management of meter reading and charging efficiently in electric power market.

\section{Current Situation of Meter Reading and Charging in Electric Power Enterprises}

In the enterprise management of power system, meter reading, accounting and charging are three important aspects of power management. Among them, the meter reading is the primary part of its management work. Meter reading work is the process of transcribing and recording that the meter reader adopt different meter reading way to copy the charges according to the user's electricity meter in the electric power enterprise. It is the data indicator of the user's power consumption. At present, the common way of meter reading are mainly tow methods, which are copying by meter reading machine and obtaining automatically. The former is realized by the recorder's on-site copying of data. The latter achieves the system automatically entering data, but both of them cannot to solve the demand of the quality and efficiency in the electric power development. At the same time, the current meter reading way still cannot provide accurate and real-time recorded data. And, it is still easy to appear the phenomenon of wrong meter readings and miss meter readings in the records, in aspects such as pricing, power analysis, line loss control, the marketing forecast and so on, which has brought a certain extent influence to the economic benefits of the power enterprises. Therefore, how to effectively improve the quality and efficiency in the process of meter reading and charging is a key problem to be solved urgently in the management development of power enterprises.

\section{Disadvantages of Meter Reading, Checking and Charging in Power Management System}

Traditional power management mode is generally adopted in power application system, and there are many unavoidable disadvantages in power management, mainly reflected in the following aspects.

\subsection{The less rigorous meter reading work}

At present, the workload of meter reading is getting larger and larger, and the precision of work is getting less and less rigorous due to the complexity of the interlaced power system. Some meter 
readers give an estimated measurement on the user's electricity consumption. According to the many years' experience of meter reading and the information of the line loss indicator, in order to quickly complete the electricity meter reading work, power usage is inconsistent with the actual record, which affects the credibility of the power system, and causes direct economic losses to the user and the electric power enterprise.

\subsection{Adjustment in nature of electricity consumption without permission}

In the application of electricity, the power plant employee modify the nature of electricity consumption in order to complete the electricity line loss index which the superior directed. They keep the total amount of electricity charges unchanged while increasing the power consumption of the users, thus reducing the line loss rate; On the basis of completing the line loss index, some employees also change the nature of electricity consumption and put the electricity income which beyond the total amount of electricity income into their own use.

\subsection{Electricity stealing and electric leakage in countryside and risks in charging}

Rural power system brought an opportunity to power stealers with a big amount and wide range of low-voltage user. The number of meters in the countryside is relatively much more, and the user's energy consumption is small, which caused the phenomenon of stealing electricity is not easily be detected. At the same time, some electricians take advantage of their own responsibilities to install power consumption devices within their own jurisdiction, and finally collect the electricity charges and installation fees into their own pockets. Generally, the charge of electricity charges is mainly handed over to the electrician to carry out, that is, there are two main risks in the recovery of electricity charges. On the one hand, it is easy to have a risk in capital turning in. On the other hand, it has the risk that the quality and culture of the toll collectors impact on the capital. So in the process of electricity charging, the electric power enterprise have to cultivate specialized high-quality staff, and unify the collection and verification of the electricity charges to reduce the link of electricity charges payment and reduce the risk of electricity recovery.

These common disadvantages brought a certain extent trouble to the management work of the electric power enterprise, and brought directly harm to the enterprise's economic benefits, and brought negative influence to the image of the enterprise. Therefore, it is necessary to increase the inspection strength of meter reading, checking and charging work in the management of electric power enterprise, continuously improve the overall quality of electric power staff, at the same time, and separately process the management work of meter reading, checking and charging, and clear the labor division of each department, mutual collaboration and mutual restraint, thus high efficient power management system is established.

\section{Specific Measures on Improving the Efficiency and Quality of Meter Reading, Checking and Charging}

The mode of traditional power management cannot solve the abuses in metering and charging work now already. So the electric power enterprise should be fully prepared to carry out the three link work of meter reading, checking and charging, and specific measures are described in detail.

\subsection{Timely and well conduct the publicity of the meter management and charging system}

Professional training should be held by electric power enterprises according to the function of each department. Each department's work should be reasonable arranged, the existing rules and regulation should be timely perfected, and regular assessments and tests be held on the enterprise employees, the connection of the work be done well to ensure that there are someone who is in charge of its own part in the management of meter reading, checking and charging. Enterprises should strengthen the publicity of the unit price of electricity, and every household should be involved into the publicity. The publicity work should be carried out in combination with radio, newspaper and television, so as to realize of the users' comprehensive understanding of the electricity price and provide guarantee for the classified implementation of electricity price. 
In the electric power work of meter reading, checking and charging, these three work closely related. The electric power enterprise should regularly carry out meetings on different levels, and timely put forward the problems existing in the power development now. The superior should give correct attention and solution to mobilize the work enthusiasm of grass-roots meter readers and other staff, suitably do some propaganda works on electricity charging, and make electricity service be carried out into the masses of users, to enhance the image of the corporate, and improve economic benefits of the enterprise.

\subsection{Reasonably arrange the division of the staff}

In the management of the electricity charging system, the first thing is to clear the requirements of the employees in the work link of meter reading, checking and charging. Specialized agencies shall be set up to operate it. The three parts are independent from each other, and directly be given a unified management by the supervisor, at the same time. First of all, the main work of meter reading is that the staff should accurately record the data of the meter and ensure the real-time data transmission and timely settlement at the same time. In the arrangement of the meter reading work, it has to change effectively according to the actual situation of the meter reading work. For example, the meter readers can be divided into sections according to the size of the meter reading workload, and then everyone collaborates in their own different area to speed up the work progress, and improve the efficiency of the work. The accounting center should be assigned professional staff to make statistical analysis on the data transmitted sent by the meter reader, and make a good assessment on line loss, electricity price and electricity business accounting. In the recovery of electricity charges, special banks can be used for business collection. In some areas, appropriate electricity recovery classes may be established. Meanwhile the electric power enterprise can divide into different maintenance levels according to the function of each department to make the department division and personnel responsibility be known clearly, and carry on the unification management to perfect the charging system structure of the electric power enterprises, put on comprehensive management on it by using specialized management mode, so as the economic efficiency and the service level of enterprises be improved.

\subsection{Strengthen the management of meter reading, pay attention to the calculation of electricity charging, and improve fee-paying work}

Meter readers should be accurate in meter reading. The development of meter reading work should be based on the authenticity of meter reading code, the nature of electricity consumption and the completion time of meter copying, so as to ensure that there is no phenomenon of missing copy, wrong copy and estimated copy in the area. The accounting work of electric charges should be carried on centralized management. And, the personal responsibility must cleared to accomplish no "more and wrong charging". The verification of electricity charges is an important link in the management of electricity charges, which is mainly carried out from such aspects as the number of users, classified statistics of the electrical properties, line loss rate, average electricity price, etc. The work of charging should be checked and proofread by special accountants to avoid large errors in the work of charging.

\section{Conclusion}

Enterprises should focus on comprehensively centralized management and make sure that the appraisal management method be constantly improved at the same time, make sure a perfect supervision system be established, and a unified management be carried out by using technical means, meanwhile the management of all kinds of electricity meter measurement and the propaganda work of electricity prices be done well, and the publicity should be strengthened, so as to establish a good image for the development of the enterprise and improve economic benefits for the enterprise, make sure a qualitative leap be brought to the development of the enterprise. 


\section{References}

[1] Yu fuhui. A brief discussion on meter reading fees and quality services [J]. Enterprise technology development: the second half of the month, 2010,29 (9) : 132.

[2] Zhang jinhu, Hu xuejun. Brief talk about the problems and countermeasures occur in the rural electrician's meter reading and charging [J]. China science and technology review, 2011, (19) : 312.

[3] Yao zhanfeng, Kang honglei. Brief talk about the problems and countermeasures of meter reading and charging $[\mathrm{J}]$. China e-commerce, 2012, (24) : 51.

[4] Wang jun, Cao ninghong. Measures to improve the efficiency of meter reading, accounting and charging [J]. Information on economic and technological cooperation, 2010, (31) : 100. 